\title{
Factors Affecting the Mechanical Properties Variation after Annealing Of Cold Rolled Steel Sheet
}

\author{
Ruangyot Wichienrak ${ }^{1}$, and Somchai Puajindanetr ${ }^{1}$ \\ ${ }^{1}$ Industial Engineering, Faculty of Engineering, Chulalongkorn University, Bangkok, Thailand
}

\begin{abstract}
Cold rolled steel industry in type of batch annealing furnace, the mechanical properties of steel sheet have variation by each position. The parameters of annealing temperature and time were analysed to work out the source of mechanical properties variation. This experiment is using low-carbon steel sheet that were cold rolled at the same reduction ratio. Then annealed applying by different annealing temperature and soaking time in laboratory furnace. The mechanical properties which were examined. Yield strength, Tensile strength, \%Elongation and Hardness. The result showed that (1) Increasing the annealing temperature could remarkably decrease the yield strength, tensile strength and hardness, whereas the \%Elongation could be increased. (2) Increasing the soaking time could slightly effect on mechanical properties. (3) The annealing temperature of $650^{\circ} \mathrm{C}$ with soaking time of $2 \mathrm{hr}$ should be applied to provide the mechanical properties close to target value (4) Grain size of the workpieces trended to be grown from the annealing temperature of $610^{\circ} \mathrm{C}$.The experiment it can be concluded that annealing temperature and soaking time have significant effect on the mechanical properties variation in batch annealing.
\end{abstract}

\section{Introduction}

Cold rolled steel sheet is base material in many industries such as automobile, home appliance, furniture, machine equipment, and it is raw-material of galvanize steel industries.

Cold rolled steel sheet in coil is made by hot rolled coil steel sheet in coil. It starts from pickling to remove oxide and dirt by acid and then cold rolling occurs below recrystallization temperature (Room temperature) which increase strength and it also improves surface finish to be flat and shiny and holds tighter tolerance of dimension. The steel after rolling, the steel sheet is called cold rolled full hard. At this stage steel sheet is not suitable for drawing. Then annealing process is applied to get recrystallization. After annealing material become softer and good for drawability usage.

In the view of quality in cold rolled steel sheet product are dimension, surface quality and mechanical properties etc. This research is studied at conventional cold rolling steel sheet process in Thailand, the layout of batch annealing furnace is shown as Figure 1(a).

Annealing process is importance process to control mechanical properties of product, at this process 4 steel coils were put into furnace. And then $\mathrm{H}_{2}$ atmosphere was applied to avoid oxidation on steel strip surface at high temperature and transfer heat from furnace pass through steel coil. There are 3 stages of annealing. Heating stage, temperature is up to target temperature. Soaking stage, temperature is hold for getting the homogeneous temperature between outside and inside of steel coils.
And last stage is cooling, temperature is cooling slowly in furnace.

The variation of mechanical properties occurs at each position of steel coil length. (Outside, middle and inside of steel coil) By this reason, some portion of steel were found the mechanical properties problems.

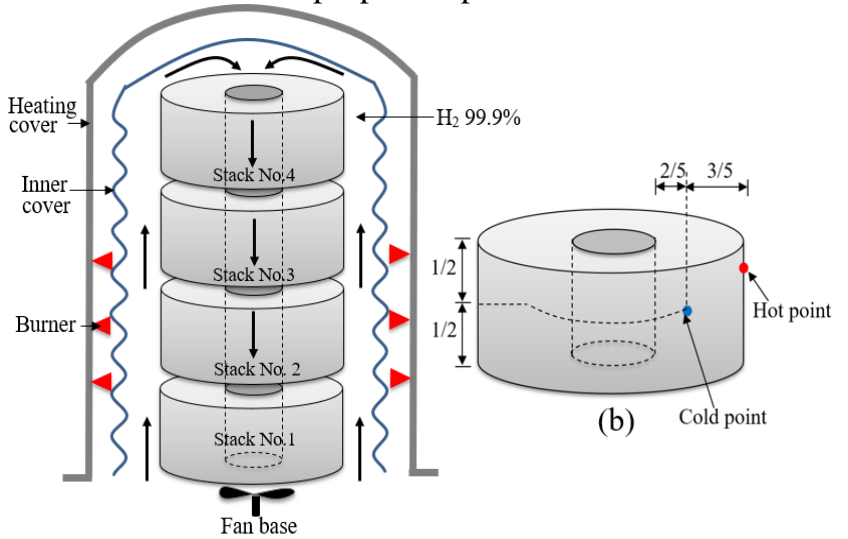

(a)

Figure 1. (a) Layout batch annealing furnace of steel coil (b) Position of thermocouple in coil (Hot \& Cold point)

In order to get the homogeneous temperature between outside and inside of steel coils. Annealing process is controlled by using thermocouples sensor attach on steel strip by 2 positions of steel coil at stack no. 1 . Hot point is at outside of steel coil and cold point is at $2 / 5$ of side wall by inside coil. The position is shown as Figure 1(b).

\section{Production problem background}


There are several steel types of production cold rolled steel sheet in coil. The mainly production is low-carbon steel in thickness $1.0 \mathrm{~mm}$. There are 3 main mechanical properties problems of production which were (1) the \%Elongation, (2) Yield strength, (3) Hardness of 46, 33 and $16 \%$ of the total problems, respectively.

Usually, when steel coils are finished production. The mechanical properties were examined at outside of coil (Hot point), middle of coil (Near cold point) and inside of coil. The value must be within control range all positions.

\section{$2.1 \%$ Elongation}

(a) Outside coil (Hot point) being the $\overline{\mathrm{x}}$ of $41 \%$

$\mathrm{C}_{\mathrm{p}}$ of 1.60 and $\mathrm{C}_{\mathrm{pk}}$ of 0.81

(b) Middle coil (Cold point) being the $\bar{x}$ of $39 \%$

$\mathrm{C}_{\mathrm{p}}$ of 2.16 and $\mathrm{C}_{\mathrm{pk}}$ of 0.57 , data is shown as figure 2 .

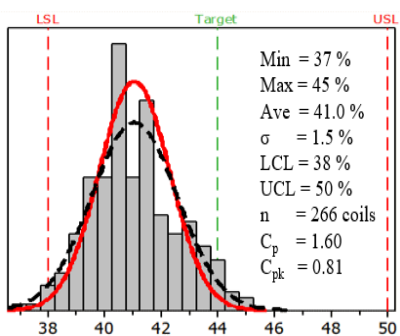

(a) Elongation (\%)

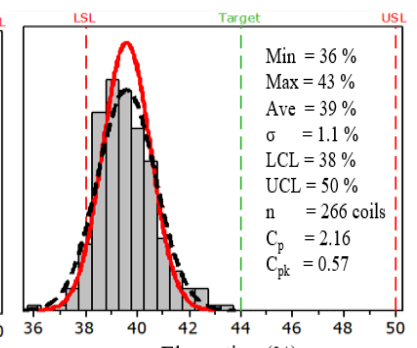

(b) Elongation (\%)
Figure 2. Histogram data of \%Elongation (a) at hot point position (b) at cold point position.

\subsection{Yield strength}

(a) Outside coil (Hot point) being the $\overline{\mathrm{x}}$ of $239 \mathrm{MPa}$ $\mathrm{C}_{\mathrm{p}}$ of 1.81 and $\mathrm{C}_{\mathrm{pk}}$ of 0.91

(b) Middle coil (Cold point) being the $\bar{x}$ of $250 \mathrm{MPa}$ $\mathrm{C}_{\mathrm{p}}$ of 2.93 and $\mathrm{C}_{\mathrm{pk}}$ of 1.07 , data is shown as figure 3 .

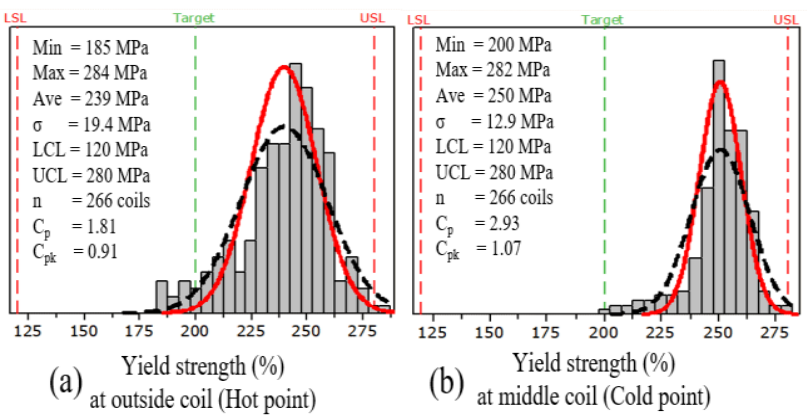

Figure 3. Histogram data of Yield strength (a) at hot point position (b) at cold point position.

\subsection{Hardness (HRB)}

(a) Outside coil (Hot point) being the $\overline{\mathrm{x}}$ of $52 \mathrm{HRB}$ $\mathrm{C}_{\mathrm{p}}$ of 2.87 and $\mathrm{C}_{\mathrm{pk}}$ of 1.13

(b) Middle coil (Cold point) being the $\bar{x}$ of $54 \mathrm{HRB}$ $\mathrm{C}_{\mathrm{p}}$ of 3.36 and $\mathrm{C}_{\mathrm{pk}}$ of 0.97 , data is shown as figure 4 .

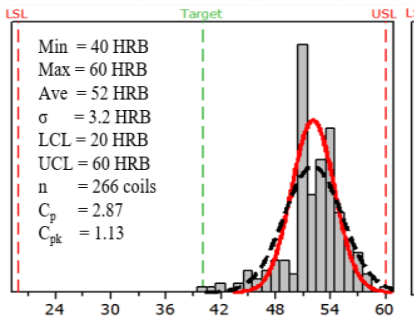

(a) Hardness (HRB)

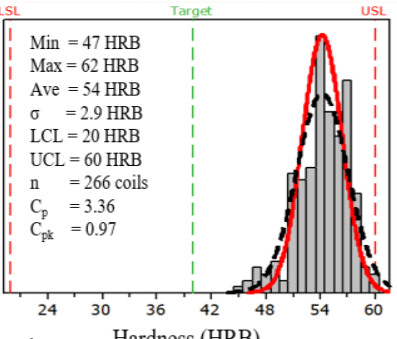

(b) Hardness (HRB)
Figure 4. Histogram data of Hardness (a) at hot point position (b) at cold point position.

\subsection{Annealing profile}

The data of annealing profile is shown as figure 5 The temperature at outside coil (Hot point) is up to target temperature before middle coil (Cold point) around $5 \mathrm{hr}$. the difference temperature between 2 position effect to variation of mechanical properties.

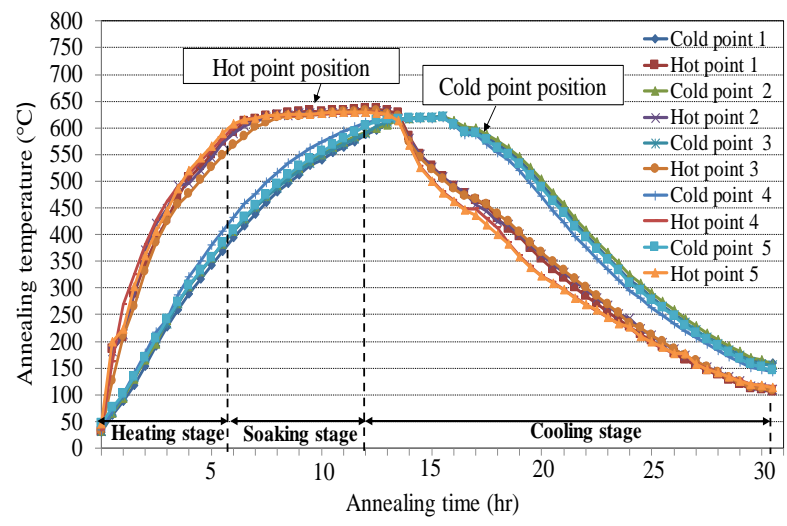

Figure 5. Annealing temperature versus time of 5 sample coils at hot point and cold point position.

\section{Factor effecting the mechanical properties of cold rolled steel sheet.}

There are many factors affecting the mechanical properties of cold rolled steel sheet, Example as cold rolling reduction ratio increase, recrystallization temperature and recrystallization soaking time significantly decrease [1]. In order to obtain the extreme high strength of pearlitic steel sheet, it is favorable to increase the cold-rolling reduction ratio (at least 90\%) to achieve the solid solution hardening effect [2].

In Batch Annealing, temperature of strip depends upon thickness, width, weight and stack position of the coil. Width range of coil and weight range of coil have significant effect on the mechanical properties variation in batch annealing. Decreasing the width range leads to the decreasing the spread in yield strength within the stack [3]. Amount of coil in batch annealing furnace slight effect the difference temperature between hot point and cold point [4] In the annealing stage, heating rate and soaking time obviously have higher intrinsic effects on formability properties. The coil position in the batch annealing furnace has a slight effect on n-value but more effect on $r$-value [5]. A low carbon steel sheet with 
$0.035 \% \mathrm{Cr}$ responded positively to continuous annealing exceed to $700{ }^{\circ} \mathrm{C}$ with fully recrystallized grains [6]. The minimum temperature of cold point to meet the mechanical properties were $654-678^{\circ} \mathrm{C}$, respectively. And the temperature of cold point are lower than hot point ranging from about $17-46^{\circ} \mathrm{C}$ [7].

There is the research gap about chemical composition and the difference of cold reduction ratio and other facility for study in this research.

\section{Experimental method}

\subsection{Samples}

The chemical composition of low-carbon steel sheet in shown in Table 1. The steel sheets were produced at cold rolled industries at reduction ratio $65 \%$ then it was cut from quarter of coil width to size $200^{\mathrm{W}} \times 300^{\mathrm{L}} \mathrm{mm}$.

Table 1. Chemical composition of samples (wt\%)

\begin{tabular}{|c|c|c|c|c|c|c|}
\hline $\mathbf{C}$ & $\mathbf{S i}$ & $\mathbf{M n}$ & $\mathbf{P}$ & $\mathbf{S}$ & $\mathbf{A l}$ & $\mathbf{F e}$ \\
\hline 0.04 & 0.01 & 0.24 & 0.014 & 0.007 & 0.044 & Balance \\
\hline
\end{tabular}

Steel sheet thickness is $1.0 \mathrm{~mm}$.

\subsection{Annealing condition}

Annealing temperature and soaking time is shown as table 2. Laboratory-Furnace (Nabertherm C30) is used for this experiment. The heating rate is fixed at $100^{\circ} \mathrm{C} / \mathrm{hr}$. The annealing profiles is shown as figure 6 .

Table 2. Annealing condition

\begin{tabular}{|c|c|}
\hline Annealing temperature $\left({ }^{\circ} \mathbf{C}\right)$ & Soaking time (hr) \\
\hline $570,610,650,700$ & $0.5,1,2$ \\
\hline
\end{tabular}

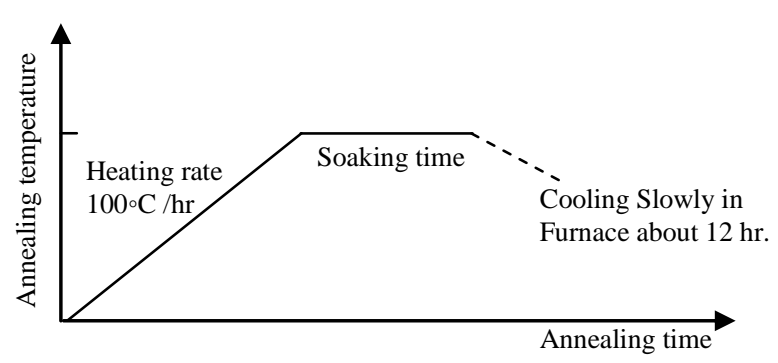

Figure 6. Annealing profile of the experiment.

\section{3) Testing equipment \& method}

Tensile test* samples were tested in rolling direction by using Instron model 5982. Follow JIS Z2241:2011

Hardness test* sample were checked by using a Rockwell scale B (HRB) Follows JIS Z2245:2016

Microstructure samples were cut by rolling and transverse direction then observe structure the thickness side on magnification $100 \mathrm{X}$ by using optical microscope.

*Check at laboratory certified of ISO/IEC 17025.

\subsection{Mechanical properties}

The result is shown the relationship between mechanical properties Yield strength, Tensile strength, Elongation, Hardness and annealing temperature \& soaking time are shown as figure 7-10.

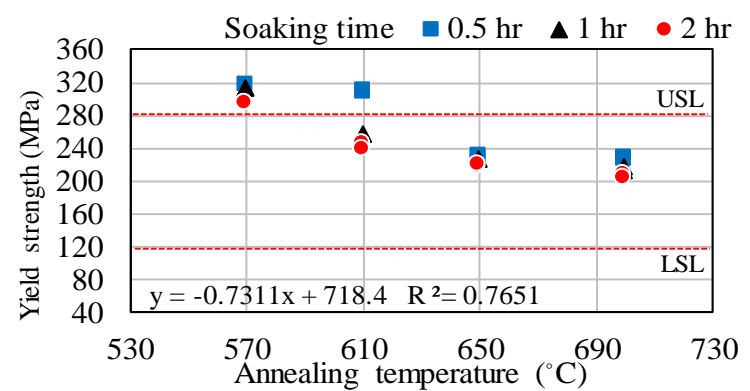

(a)

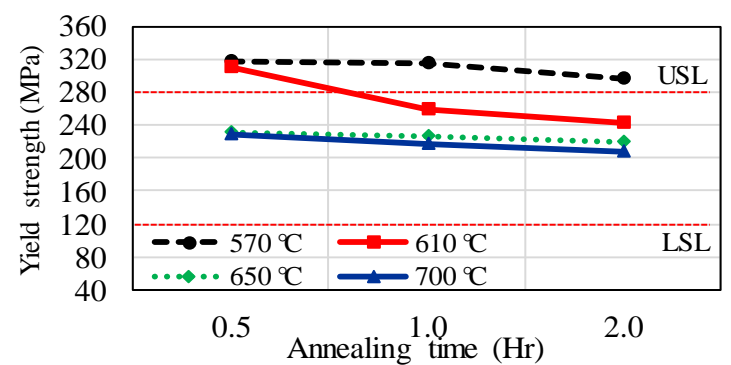

(b)

Figure 7. (a) Result Yield strength versus annealing temperature (b) Interaction plot for Yield point

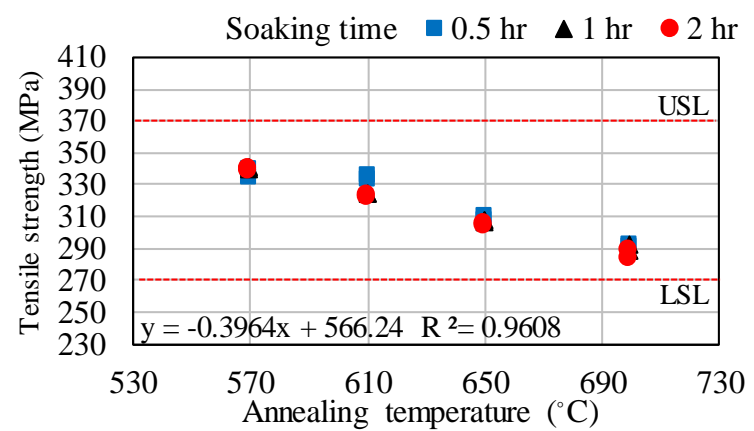

(a)

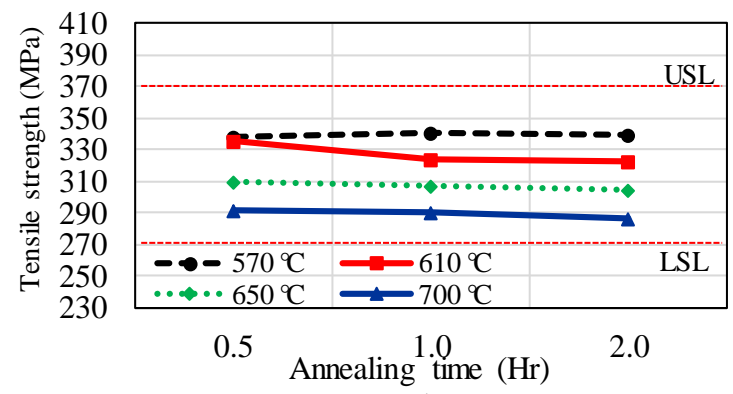

(b)

Figure 8. (a) Result Tensile strength versus annealing temperature (b) Interaction plot for Tensile strength. 


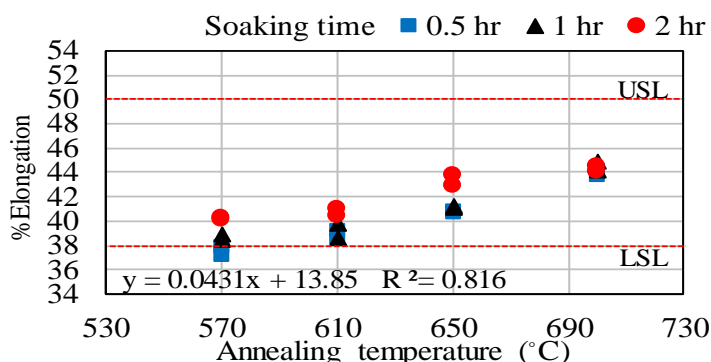

(a)

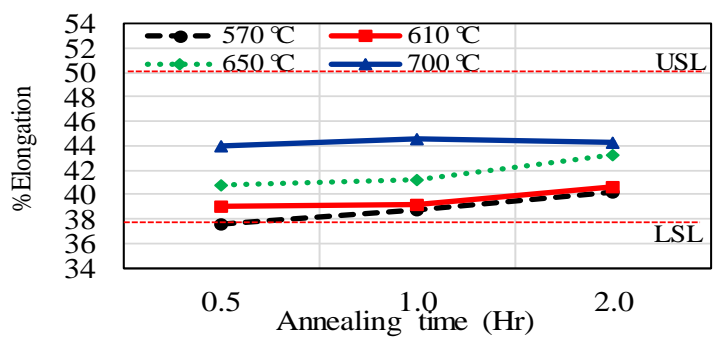

(b)

Figure 9. (a) Result \%Elongation versus annealing temperature (b) Interaction plot for \%Elongation

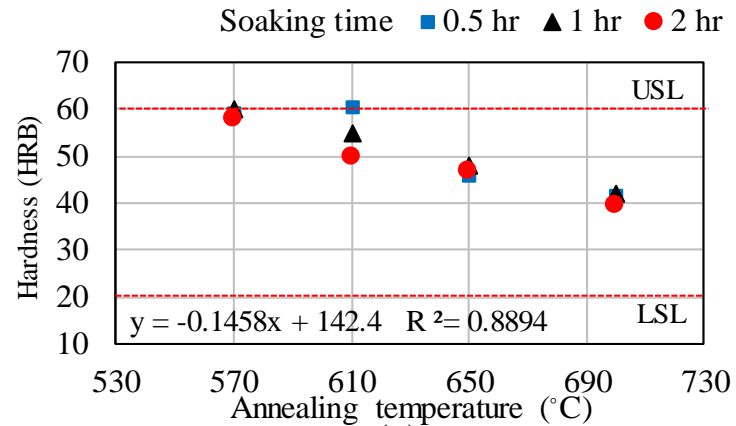

(a)

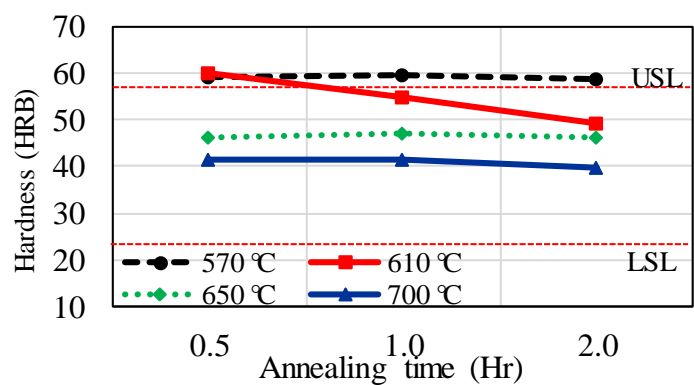

(b)

Figure 10. (a) Result Hardness versus annealing temperature (b) Interaction plot for Hardness

Analysis P-value (ANOVA), the significant of factors is shown as table 3 .

Table 3. P-value test of mechanical properties

\begin{tabular}{|c|c|c|c|c|c|}
\hline \multirow{2}{*}{ Source } & \multicolumn{4}{|c|}{ P-value } & Resul \\
\cline { 2 - 5 } & YP & TS & \%El & HRB & t \\
\hline $\begin{array}{c}\text { Annealing temp } \\
(\mathrm{T})\end{array}$ & 0.000 & 0.000 & 0.000 & 0.000 & $*$ \\
\hline Soaking time $(\mathrm{t})$ & 0.000 & 0.000 & 0.000 & 0.000 & $*$ \\
\hline Interaction $(\mathrm{T}) *(\mathrm{t})$ & 0.000 & 0.003 & 0.013 & 0.000 & $*$ \\
\hline R2 & 99.87 & 99.55 & 98.27 & 99.45 & - \\
\hline
\end{tabular}

Remark * Significant, P-value $<\alpha 0.05$
Figure 11. Shows the mechanical properties results were interpolated to be percentage from $0 \%$ of LSL to $100 \%$ of USL. In order to find the optimize point that the nominal value should be $50 \%$.

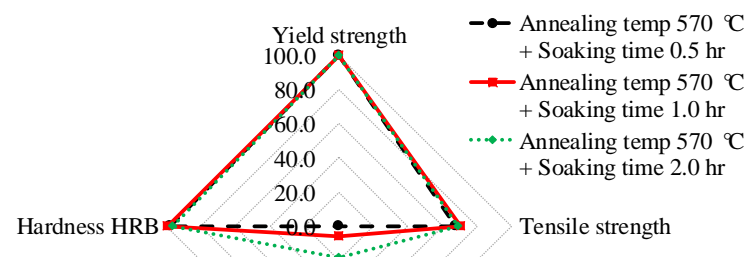

Elongation

(a)

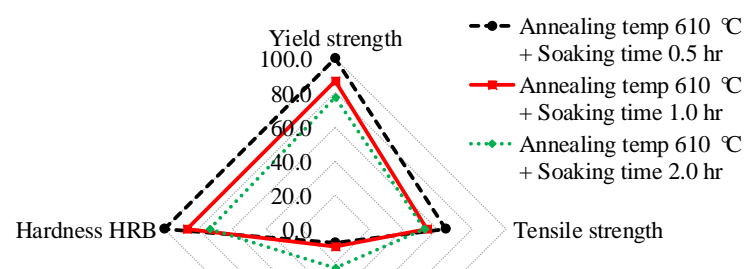

Elongation

(b)

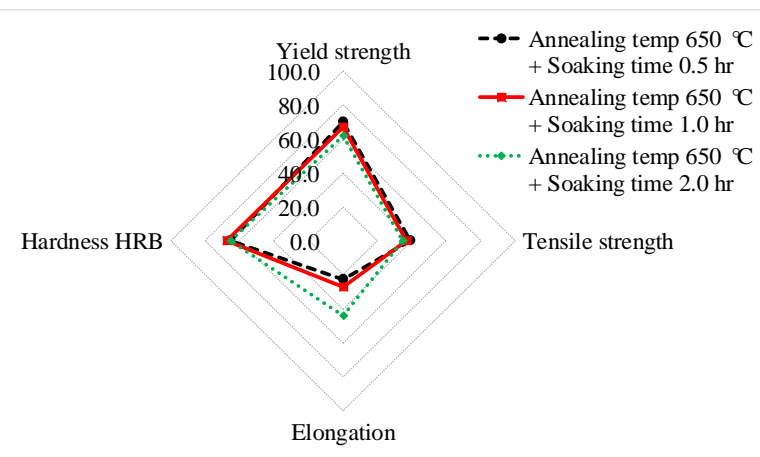

(c)

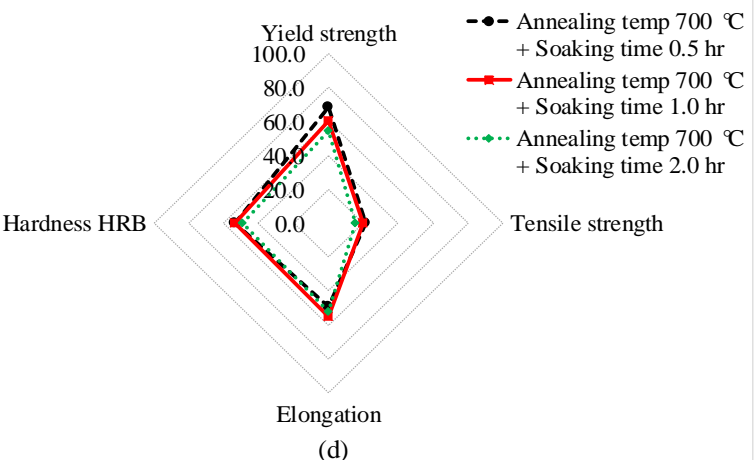

Figure 11. Mechanical properties plot of yield strength, tensile strength, Elongation, Hardness by each soaking time 0.5, 1.0, $2.0 \mathrm{hr}$ (a) Annealing temp $570{ }^{\circ} \mathrm{C}$ (b) Annealing temp $610^{\circ} \mathrm{C}$ (c) Annealing temp $650^{\circ} \mathrm{C}$ (d) Annealing temp $750^{\circ} \mathrm{C}$

\subsection{Microstructure}


The microstructures were examined to observe grain size and recrystallization structure before and after applying by different annealing temperature. The results are shown as Figure 12-14.

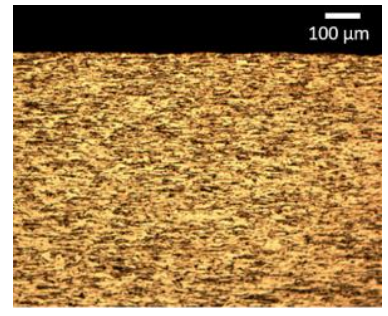

(a)

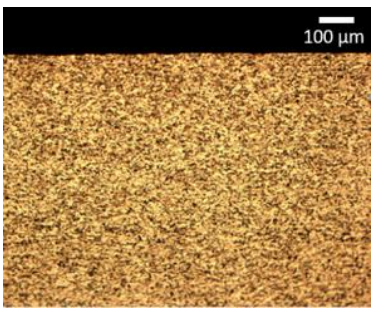

(b)
Figure 12. Microstructure of sample before annealing (a) Rolling direction (b) transverse direction

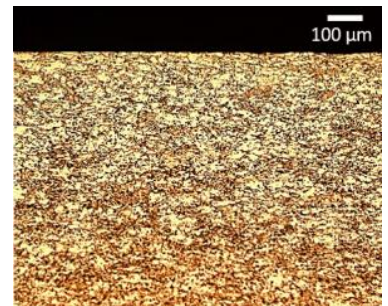

(a) $\mathrm{T}=570^{\circ} \mathrm{C}$

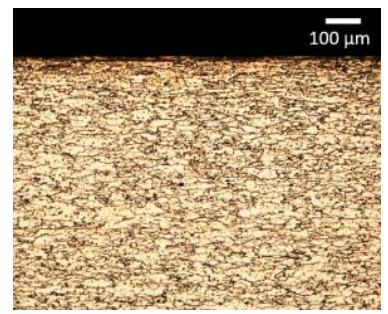

(a) $\mathrm{T}=610^{\circ} \mathrm{C}$

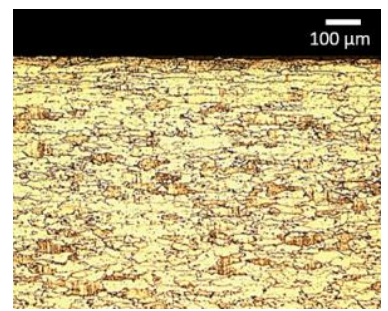

(a) $\mathrm{T}=650^{\circ} \mathrm{C}$

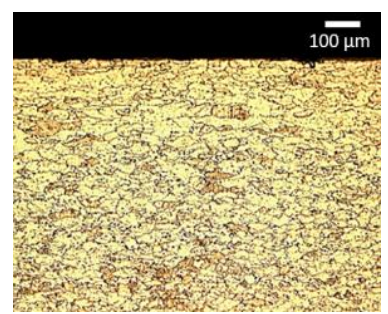

(a) $\mathrm{T}=700 \circ \mathrm{C}$

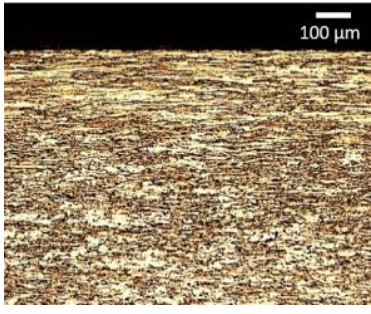

(b) $\mathrm{T}=570^{\circ} \mathrm{C}$

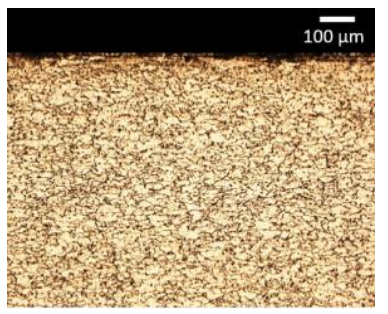

(b) $\mathrm{T}=610^{\circ} \mathrm{C}$

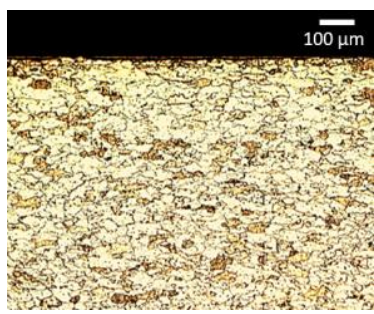

(b) $\mathrm{T}=650^{\circ} \mathrm{C}$

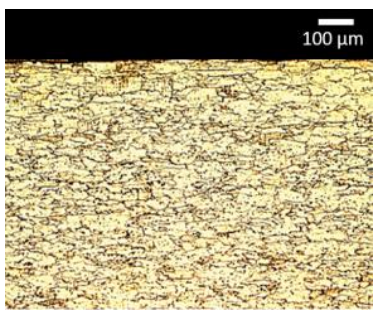

(b) $\mathrm{T}=700 \circ \mathrm{C}$
Figure 13. Microstructure of sample after annealing at temperature (T) with soaking time $1 \mathrm{hr}$ at (a) Rolling direction (b) transverse direction (a) $\mathrm{T}=570{ }^{\circ} \mathrm{C}$

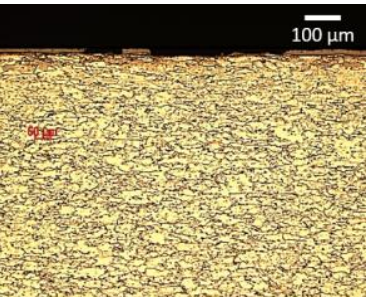

(a) $\mathrm{T}=610 \circ \mathrm{C}$

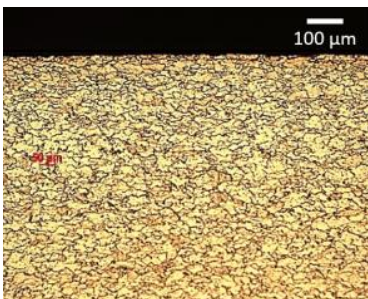

(a) $\mathrm{T}=650{ }^{\circ} \mathrm{C}$

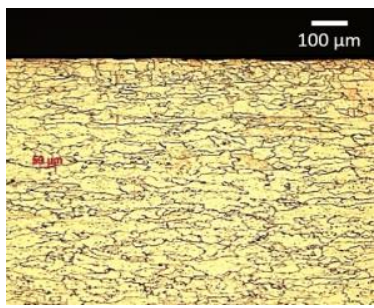

(a) $\mathrm{T}=700{ }^{\circ} \mathrm{C}$

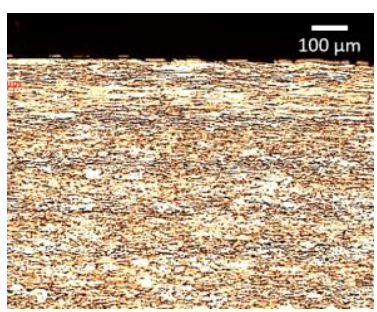

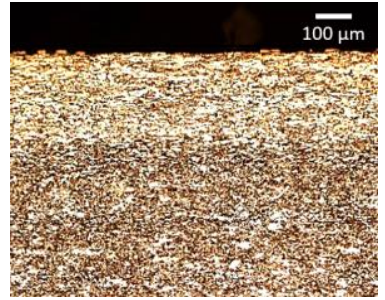

(b) $\mathrm{T}=570{ }^{\circ} \mathrm{C}$

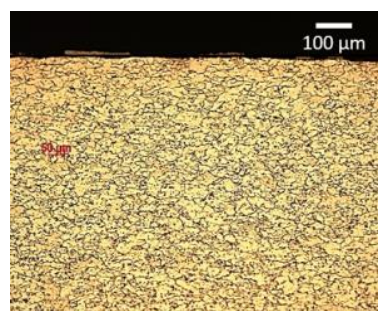

(b) $\mathrm{T}=610 \circ \mathrm{C}$

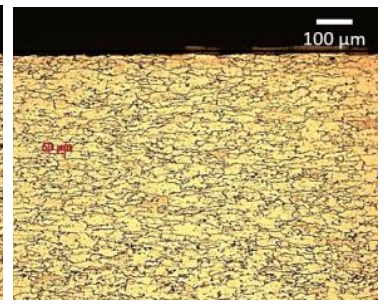

(b) $\mathrm{T}=650{ }^{\circ} \mathrm{C}$

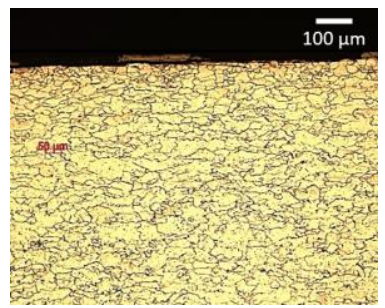

(b) $\mathrm{T}=700{ }^{\circ} \mathrm{C}$

Figure 14. Microstructure of sample after annealing at temperature ( $\mathrm{T}$ ) with soaking time $2 \mathrm{hr}$ at (a) Rolling direction (b) transverse direction

\section{Conclusion}

From the experiment it can be concluded that annealing temperature and Soaking time have significant effect on the mechanical properties variation in batch annealing.

1) Increasing the annealing temperature could remarkably decrease the yield strength, tensile strength and hardness, whereas the \%Elongation could be increased.

2) Increasing the soaking time could slightly effect on mechanical properties.

3) The annealing temperature of $650^{\circ} \mathrm{C}$ with soaking time of $2 \mathrm{hr}$ should be applied to provide the mechanical properties close to nominal value which provide yield 
strength, Tensile strength, \%Elongation and Hardness were of $220 \mathrm{MPa}, 305 \mathrm{MPa}, 43 \%, 46 \mathrm{HRB}$ respectively. 4) Grain size of the workpieces trended to be grown from the annealing temperature of $610^{\circ} \mathrm{C}$.

\section{References}

1. D. Zhuang, Lei-gang Wang, Yao Huang. Microstructure and texture evolution during recrystallization of low-carbon steel sheet, Journal of Iron and Steel Research, International 24, 84-90 (2017)

2. Y. Liu, C.D. Yang, M. Liu. Effects of microstructure and crystallography on mechanical properties of cold-rolled SAE1078 pearlitic steel, Materials Science \& Engineering A 709, 115-124 (2018)

3. R. Kr Singh, Sudharshan R. Optimization of annealing stack using design of experiment method in Batch Annealed HSLA Steel, Materials Today: Proceedings 5, 7055-7060 (2018)

4. N. Watcharaprapaipan. Modeling batch annealing process in cold rolled steel sheet industry, Thesis of Chulalongkorn University (2009)

5. H. Monajati a, D. Asefi. Analysis of the effects of processing parameters on mechanical properties and formability of cold rolled low carbon steel sheets using neural networks, Computational Materials Science 49, 876-881 (2010)

6. R. Mendoza a, A. Molina. Mechanical properties of a recrystallized low carbon steel, Scripta Materialia 48, 391-395 (2003)

7. F.A.N.G. Chun-Jen, W.U. Li-Wen. Batch Annealing Model for Cold Rolled Coils and Its Application, China Steel Technical Report 28, 13-20 (2015) 